\title{
Study and Practice of Teaching Methods of Pharmacy Administration Based on Interactive Teaching Mode
}

\author{
Wen Zhengshun ${ }^{\text {a }}$, Qu Youle \\ School of Food and Medicine \\ Zhejing Ocean University \\ Zhoushan, Zhejiang 316022, China \\ a zswenmr@163.com
}

\begin{abstract}
Classroom teaching mode is the "intermediary" between teaching theory and classroom te aching practice, and it is the unification of teaching theory and practice. The interactive teaching mode mobilizes students' enthusiasm and enhances the ir passion for learning and awareness of participation. Pharmacy Administration is an important part of the pharmacy curriculum and it is a discipline that requires strong practicality. In recent years, the research group has carried out study and exploration of the interactive teaching mode of Pharmacy Administration. It proves that the interactive teaching mode can better combine the theoretical study and practice of Pharmacy Administration and greatly promote the learning participation of students. It can well integrate relevant technical, normative and descriptive course content with Pharmacy Administration activities, hence improving students' initiative and the teaching effects.
\end{abstract}

Keywords_-interactive; Pharmacy Administration; teaching

\section{INTRODUCTION}

The classroom teaching mode is built under the guidance of certain teaching ideas and theories and it is a relatively stable teaching procedure and a system of method and strategy in the classroom teaching process. Pharmacy Administration is a compulsory course for pharmacy major. It is of great significance to improve the practice and administration ability as well as R\&D of pharmacy of undergraduate students majoring in pharmacy major. It is an important basis of $R \& D$ and administration work of pharmacy after graduation and it is one of the professional skills that students have to master. According to the recent graduates' employment of this major, it is found that many graduates are employed in the pharmacies of major hospitals, mainly engaging in Pharmacy Administration and other related work. This also put forward more requirements for the cultivation of teaching practice ability in the Pharmacy Administration course. However, students tend to be tired of learning, have poor enthusiasm and have low passion for active learning when studying professional courses. Delivering vivid and systematic knowledge of professional courses is the fundamental task of professional teachers; stimulating students' passion for learning is the primary duty of teachers. The learning effects can be good by ensuring that students are active and enthusiastic in class, hence forming good teaching interactive atmosphere and

Fund project: Zhejiang Higher Education Classroom Teaching Reform Project "Exploration of the Interactive Teaching Mode of Pharmacy Administration” (kg2013208). achieving the goal, namely teaching benefits teachers as well as students. At present, many courses are still being taught following the traditional teaching method, namely teachers lecture more while students are less participated. Teaching is still a one-way output process. Students are in a passive learning state, which is an ine vitable result of infusion teaching and the inefficiency of learning. Learning itself should be a conscious behavior. It is a key issue that must be solved in teaching reform of methods to improve students' enthusiasm for learning and awareness of participation, and to change passive learning into active learning.

\section{THEORETICAL BASIS AND RESEARCH GOALS}

\section{A. Theoretical Basis}

1. Cognitive psychology research shows that the process of students' knowledge formation is the process of interaction between external information and the original knowledge and thinking structure of students. The ability of students is formed with activities as an intermediary and it is an important psychological feature of adolescents to think in activities and conduct activities in thinking. The results of modern psychology research also show that multi-directional communication combines teacher-student communication with peer-to-peer communication and it is a kind of communication mode that enjoys high efficiency and the best team atmosphere, and the members are easy to form communication skills [1, 2].

2. Classroom teaching activities are a dynamic balancing process in which multiple factors interact, depend on each other, and restrict each other. Piaget proposes constructivist theory in his book Constructivist Learning Theory, namely learning should not be seen as a passive acceptance of the knowledge lectured by the teacher, but as an active constructive activity of the learner based on his or her original knowledge and experience. It means that the process of students learning knowledge is not based on the infusion of teachers. Students should consciously construct new knowledge based on the existing knowledge and experience, so that their cognitive structure tends to be stable and perfect. Therefore, the core of the current construction of a new teaching model, namely the key to deepening the teaching reform is how to give full play to the initiative, enthusiasm and 
creativity of students in the learning process, so that students can truly become the subject of information processing and the active constructor of knowledge in the learning process rather than the passive recipient of external stimuli and the object of knowledge instillation. Teachers should be the organizers and instructors of classroom teaching, and should help students promote the building of the constructivism knowledge system; while teachers should not be the indoctrinators of knowledge and the masters of the class [3, 4].

3. Cooperative learning theory. The cooperative learning theory believes that the teaching process is a process of information interaction. The teaching activity is a compound activity involving multiple interactive processes. From the perspective of modern educational information theory, the interactive mode of teaching is roughly presented as four kinds- One is one-way type. This type believes the process of teaching is that teachers pass information to students and in the process; teachers are the sender of information while students are the receiver. The second is two-way type. This type regards teaching as the interaction between teachers and students to obtain information and it emphasizes bilateral activities and timely feedback. The third is multi-directional type. The type believes that teaching is an interaction process between teachers \& students and students \& students, emphasizing multilateral interaction and mastering knowledge together. The fourth is member type. The type regards teaching as a process of equal participation and interaction of teachers and students, emphasizing that teachers, as ordinary members of the group, work together with other members and are no longer serve as the sole source of information $[5,6]$.

\section{B. Research Goals}

The core idea of "interactive teaching" fully embodies the integration of various elements of the teaching process, especially emphasizing the two most important subjects "teacher" and "student" in the teaching process with the focus of methods to fully exert their interactions and optimize the teaching process. In this way, we aim to achieve the best teaching effect, realizing the change from the original emphasis on "teaching" and neglecting "learning" to the following deviation of emphasis on "learning" and neglect 'teaching", and finally the two subjects "teaching" and "learning" begin to interact and integrate. Through the study of this topic, we explore some teaching modes that are conducive to cultivating students' innovative consciousness, reforming traditional teaching methods and means and the overall classroom teaching mode of the school, and effectively changing the way students learn; through research, we promote curriculum reform, help students establish the dignity of independence, cultivate students' sense of innovation and practical ability, gain the momentum of sustainable development and promote the development of students.

Through the implementation of this project, in order to adapt to the teaching characteristics of Pharmacy Administration in our school, the curriculum reform is carried out with classroom teaching as the main body and with the development of students as the foundation. The teaching goal is that students can skillfully apply the knowledge and skills they have learned to solve practical problems. It inspires and guides students to learn independently, and learn with inquiries and discussions. The teaching reform goals of this project can be summarized into two main aspects:

--Develop an active learning ability that is suitable for the students themselves. We aim to help students become the main body of learning under the interactive mode, master active learning methods and techniques, improve learning ability and efficiency, and better master professional knowledge and practical skills.

--Develop students' ability to express and handle problems. Through interactive learning and discussion-based learning, more students are able to participate in teaching, improving their language expression skills; through the "simulation classroom", students can better use relevant knowledge to solve problems in the Pharmacy Administration practice and better integrate learning with practice.

\section{Research PRocess AND MEAsures}

\section{A. Research Process}

\section{1) Theoretical study and formulation of research program}

In order to carry out the reform of classroom teaching mode, the research group earnestly organizes the relevant members to study the teaching theory of education, refer to the successful experience of similar classroom teaching reform, and conduct discussion and research, carry out repeated discussions, learn and argument from multiple parties, select the subject class to perform teaching reform trial, constitute the solution to the related problems involved in the interactive teaching model, and implement plan for students' self-learning. The reform of classroom teaching mode must be based on the transformation of teaching and learning concepts and it is necessary to design targeted teaching reforms based on full communication and understanding with students. For a long time, under the traditional teaching mode, students have become accustomed to the "one-way delivery" learning mode and the implementation of a new teaching mode will be a great shock of students' traditional concept and a challenge to students' personality. Affected by the traditional culture, Chinese students are introverted; especially in the classroom, they are not used to showing themselves or expressing their opinions. This topic summarizes the negative phenomena that appear in the classroom teaching process of Pharmacy Administration, such as students' lack of active learning, poor expression ability and low class participation. In view of the shortcomings in the teachings, we have selected interactive teaching classes and traditional teaching classes, adopting interactive classroom teaching mode (teacher-student interaction) and traditional teaching mode (mainly teacher-based teaching) for classroom teaching respectively. The teaching procedures mainly include classroom guidance, after-school tutoring and assignments. The interactive teaching mainly focuses on guidance of the class discussion. After class, students should preview the new content independently and propose questions of the in-class discussion. We carry out the steps with groups with the team leader takes the lead and evaluate the participation of the members. The score of this part includes in the final total score to increase student' engagement. After-school homework setting is mainly to re-absorb and understand the content of the 
class. In the process of discussion, students hand in the homework, which is conducive to cultivating students' ability to find problems and ask questions and exercising abilities to solve problems during the process of fulfillment of the homework. The interactive classroom teaching enhances students' participation, develops students' abilities to ask questions and solve problems and expression abilities, and applies book knowledge to the Pharmacy Administration practice. Through the analysis of students participation of the two groups of classroom teaching mode, the effect of completing the classroom interactive content and the classroom effect feedback survey, it can effectively reflect the effect of this teaching reform and the main elements based on the teaching process (student participation, enthusiasm and other factors)

\section{2) Interactive classroom teaching}

According to the syllabus of the major curriculum, it is an important step for students to cultivate the ability of learning content of the designated chapters independently. It is understood that the time for students in our school to prepare and review before and after class is limited, and the fulfillment of their after-class homework exists passive absenteeism. In view of this, class time is crucial for students to master professional knowledge. How to grasp the important limited 45 minutes and let students make full use of these 45 minutes to concentrate on the content of this course is the key to improve learning efficiency and it is an effective attempt for this purpose by using self-learning method of students. Students are grouped to help each other. As a multi-disciplinary marginal subject and a practical course, the course content of Pharmacy Administration needs to be combined with practical ability, which inevitably requires students to work hard in practice ability. In order to better apply this course knowledge to our Pharmacy Administration practice with efficiency, we explore the "simulation class" and combine it with group learning. We group students in the class. Students select some chapters in the course to learn in groups, exchanging learning experiences and achieving mutual learning, encouragement and common progress through the learning group. In the process of practice, the teacher instructs students to organically combine according to their different learning temperament and academic achievement, and set up a learning group, the number of members of which can be flexibly adjusted according to the practical effect. Every team will comb knowledge of the content of the chapter, design and complete the relevant problems in the simulation classroom, and come up with relevant solutions. For example, we develop a detailed "simulation classroom" interactive content for the administration of Chinese medicine pharmacies and pharmaceutical production management. Through short films and classroom communication, students find many targeted problems and study the key content of the relevant chapters with these problems, which completely changes the learning mode of rote memorization; and analyze the knowledge points in practice, which effectively improves the learning efficiency and stimulate students' enthusiasm for learning. During the interaction process, students increase their self-confidence and ability to express themselves, and raise some insightful questions and personal thoughts. Especially for these seniors that will soon graduate, it can better enrich their knowledge structure, and at the same time help them understand Pharmacy Administration and pharmacy majors in a comprehensive way, which is helpful for their employment. We can cut from these factors and they will largely enrich our teaching links and content. In the teaching atmosphere, we find that the interactive teaching mode achieves good results comparing the two types of classroom teaching modes.

\section{3) Survey feedback on classroom teaching effect}

Through the implementation of the classroom teaching reform project of interactive teaching mode of Pharmacy Administration, we select the class that is studying the course, and achieve good results in classroom teaching mainly reflected in students' enthusiasm for learning and participation. In order to understand the effect of classroom teaching more comprehensively, we design the following questionnaires to timely test the teaching effect. The members of the research team conduct questionnaire surveys of and individual interviews with the classes being taught. A total of 60 questionnaires are distributed and 60 are collected. The recovery rate reaches $100 \%$. Students pay much attention to and support for the teaching reform. Students answer the questions anonymously, which basically reflects the core issues related to teaching.

\section{TABLE I. SURVEY ST ATIST ICS ABOUT TEACHING EFFECT}

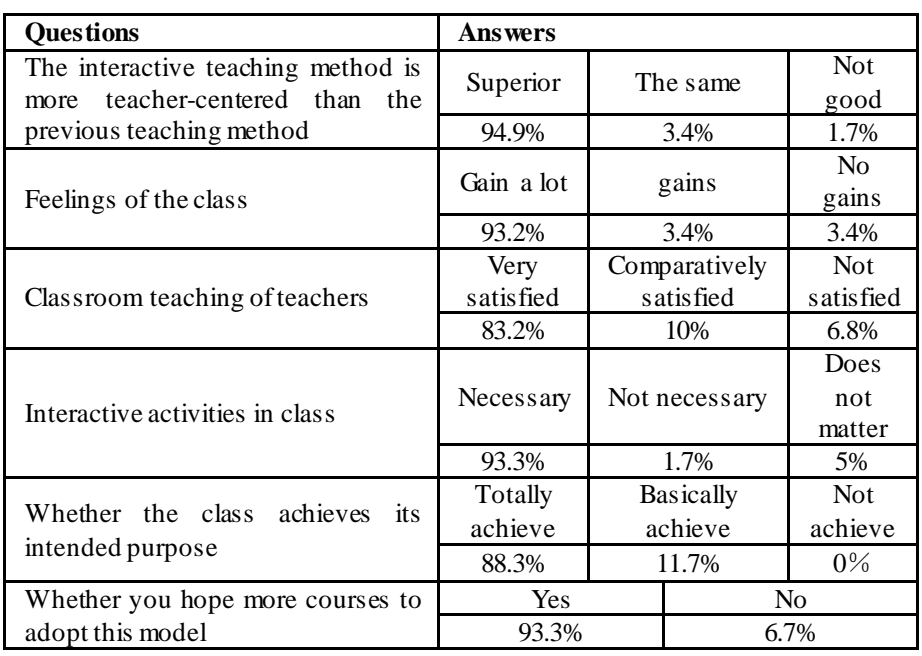

Through the analysis of the survey results, the following judgments are obtained: (1) The "student-centered" teaching model has long been neglected; it has always been "teachers lecture and students listen," and some students even have formed a formula; they are not adapted to this new model when first coming into contact with it. For example, students dare not express their own thoughts; they want teachers give them more "ready-made" and "correct" answers, more "knowledge" and so on. These ideas gradually fade and change with the advancement of teaching. In the comparison of the two teaching modes, $94.9 \%$ of the students think that the new teaching mode is superior to the traditional teaching mode. This new teaching mode is of great significance to improve the quality of teaching and fully embody the "student-oriented" educational philosophy. (2) The classroom teaching feedback is generally good. $83.2 \%$ of the students express satisfaction of the teaching and $10 \%$ are comparatively satisfied. The 
activities carried out in the classroom are recognized by most students and $93.3 \%$ of the students believe that the activities are necessary, which shows that classroom activities, one of the important contents of this model, have been recognized by most students. Through the activities, the students have an intuitive and visual understanding of the "rigid thing" like some terms and regulations in Pharmacy Administration. It is much more profound to understand and easy to remember and use. (3) The teaching effect has been affirmed by most students. 93.2\% of the students think that during the class, they have gained a lot; $88.3 \%$ of the students think that the class has fully achieved the intended purpose; $11.7 \%$ of the students think it has basically achieved the purpose. It shows that students are relatively satisfied with the teaching effect. (4) The teaching mode has been affirmed by most students. 93.3\% of the students hope that more classes will adopt this teaching mode, indicating that this teaching mode is very popular among students and it is necessary to promote it.

\section{4) Summary of the teaching effects}

The curriculum reform is based on the development of students in classroom teaching. The main body of teaching is students and the teaching objective is that students can skillfully apply the knowledge and skills they have learned to solve practical problems, inspiring and encouraging students to learn independently and learn with inquiries and discussions. The teaching reform goals of this project can be summarized into two main aspects-one is to cultivate active learning ability suitable for students themselves. Let students become the main body of learning under the interactive mode, master active learning methods and techniques, improve learning ability and efficiency, and better grasp professional knowledge and practical skills. The other goal is to develop students' ability to express and handle problems. Through interactive learning and discussion-based learning, more students can participate in classroom teaching, hence improving their language skills. Through the "simulation classroom", they can better use relevant knowledge to solve problems in Pharmacy Administration practice and better integrate learning with practice. According to the feedback of the survey, combining their own classroom teaching practice, the members of the research team seriously reflect on their own classroom teaching and learn from the successful experience, improve the inadequacies, and then apply it to the classroom teaching practice. After continuous reflection and practice, "interactive" teaching mode and its variants suitable for curriculum characteristics is formed.

\section{B. Main measures}

In the process of studying this teaching reform, we summarize during the continuous exploration, improve the program, and adopt feasible and targeted measures. The following four aspects are stated specifically:

\section{1) Grasp skillfully and penetrate organically}

The "interactive" teaching mode is in line with the spirit of the new curriculum reform, but it cannot use by rote in the experiment. We can adopt different specific operation modes according to different grades and teaching contents. In the course of operation, it is necessary to grasp organically with skills, make a distinction between levels, teach in accordance with the aptitude, and follow the principle of step by step and organic penetration.

\section{2) Adhere to the "five principles" and give full play to} students'initiative

The "interactive" teaching mode fully hand over the major position--classroom to the students, allowing students to construct and perfect their own learning methods through active learning in the time and space stage of teaching activities and laying a good foundation for lifelong learning. Therefore, we propose to adhere to the "five principles", namely more thinking, more hands-on practice, more expression, more reading and more questions. The "interactive" teaching model emphasizes the main role of students while does not neglecting the dominant position of teachers. On the contrary, it puts higher demands on teachers and requires teachers to better adapt to the new teaching mode, which is embodied in the following three aspects--have a comprehensive knowledge structure, determine appropriate teaching objectives, and rationally use modern information technology.

\section{3) Focus on exploration and optimize the classroom}

The classroom teaching mode with "interaction" as the core requires teachers to make good and flexible use of teaching materials, namely using textbooks and do not obeying the teaching materials word by word. It advocates that students should make researches, be good at asking questions, be brave in discussion; it encourages students to ask questions and different points. In this way, students are able to obtain different harvests. Teachers can't use their own teaching ideas when preparing lessons and they can't use this kind of thinking to lead students' thinking; otherwise they are not a 'helper." We believe that teachers need to prepare "teaching materials" before class, finding the connection between teaching materials and life; let students have the opportunity to choose difficulty of the class and provide controversial topics; provide basic ideas and experience to solve similar problems. And more "preparation" is in the classroom, teachers should find the confusion of students in the classroom learning and their crux of the dispute in the discussion; find out the differences in their learning; find out modes that students are willing to participate, etc.

4) Strengthen classroom knowledge and actively design teaching practice

This course designs a set of extracurricular practice internships for the application of relevant knowledge points in Pharmacy Administration, which is aimed at the lack of teaching practice and lack of links in the practice of classroom knowledge. This practice designs two parts of extra-curricular practice activities, namely research and analysis of medicine management in hospital pharmacy and drug management in pharmacy. It contains a total of 8 hours and finally students need to complete the test report. There are 17 people of A13 Medicine major and 26 people of A13 Pharmacy major participate in the practice of this course, further enhancing the students' practical ability. At the same time, as a graduate, it can help further promote their deep understanding of the major; for students whose employment direction is not clear, it can help them further consider the employment direction and find the right position as soon as possible. 


\section{CONCLUSION}

The curriculum reform is based on the development of students in classroom teaching. The main body of teaching is students and the teaching objective is that students can skillfully apply the knowledge and skills they have learned to solve practical problems, inspiring and encouraging students to learn independently and learn with inquiries and discussions. Through the methods and practice exploration of the teaching reform, students will become the learning subject under the interactive mode, mastering the relevant theoretical knowledge of Pharmacy Administration; and it can effectively apply the theoretical knowledge of the classroom to the Pharmacy Administration activities of medical institutions, improve the efficiency of Pharmacy Administration and solve problems in the practice of Pharmacy Administration, hence better integrating learning with practice.

\section{REFERENCES}

[1] Sun Zewen. Research on Interactive Classroom Teaching [D]. Central China Normal University. 2008.

[2] Long Jing. Problems and Countermeasures in Interactive Teaching Mode [J]. Teaching and Management. 2014, 10: 119-121.

[3] Li Xian, Zhang Zhenling, Li Kai, Tian Lianqi. Exp loration of Interactive Teaching Method in the Pharmacy Administration Teaching [J]. China Education Innovation Herald. 2013, 10: 57.

[4] Zhang Qi, Zheng Li, Zhang Qiu. Research on Introducing Interactive Teaching in Pharmacy Administration [J]. Journal of Guangdong College of Pharmacy. 2008, 24(4): 360-361.

[5] Jiang Yongcai, Tang Hongwei. On the Interactive Teaching Mode in College Teaching [J]. Chinese Adult Education. 2007, 4: 130-131.

[6] Wang Ting, Yi Jun, Zhao Ge, Xu Xin, Huang Yayu, Zhao Jing xia, Ling Rui. Application of Problem-oriented Interactive Teaching Method in Clinical Teaching of General Surgery [J]. Progress of Modern Biomedicine. 2015, 14(14): 2745-2747. 